\title{
EXPORTAÇÃO DE SOJA NO ESTADO DE MATO GROSSO DO SUL: CARACTERÍSTICAS DA COMERCIALIZAÇÃO
}

Enoch Felix de Oliveira Junior" Eduardo Luis Casarotto** Jane Corrêa Alves Mendonça*** Erlaine Binotto ${ }^{* * * * *}$ Michele Vasti Antônia Parlandim da Silva******

RESUMO: Nas últimas décadas, a cultura da soja assumiu importância crescente no Estado de Mato Grosso do Sul, fazendo com que as tradings companies, cada vez mais, tenham uma posição estratégica no cenário econômico regional. O Estado assumiu papel significativo no agronegócio brasileiro com destaque no volume exportado e a produtividade. Este artigo tem por objetivo caracterizar o processo de comercialização da soja exportada no Estado de Mato Grosso do Sul. Constitui-se em uma pesquisa exploratória - descritiva, com análise documental, estudo de campo, entrevistas com questionários semiestruturados e análises de dados secundários. Os resultados apontam para a importância da estratégia utilizada pelas empresas comercializadoras, o foco no cliente, para aproximar a relação com os produtores rurais. Constatou-se também que, tanto para as agroindústrias, como para as cerealistas, o preço é considerado um dos fatores cruciais para a negociação, em que a variação de centavos define a compra de um lote de soja.

PALAVRAS-CHAVE: Mato Grosso do Sul; Soja; Comercialização.

\section{EXPORTING SOYBEAN IN THE STATE OF MATO GROSSO DO SUL: THE CHARACTERISTICS OF COMMERCIALIZATION}

ABSTRACT: Soybean has had increasing importance in the state of Mato Grosso do Sul, Brazil, and trading companies are undertaking a strategic position within the regional economic scenario. The state has had a significant role in Brazilian

\footnotetext{
Bacharel em Administração pela Faculdade de Administração, Ciências Contábeis e Economia - FACE/UFGD, Brasil.

** Mestre em Agronegócios, Professor no Curso de Administração da Faculdade de Administração, Ciências Contábeis e Economia -FACE/UFGD, Brasil. E-mail: e-casarotto@uol.com.br

*** Doutora em Administração, Professora no Curso de Administração da Faculdade de Administração, Ciências Contábeis e Economia - FACE/UFGD, Brasil.

**** Doutora em Agronegócios, Professora no Curso de Administração da Faculdade de Administração, Ciências Contábeis e Economia - FACE/UFGD, Brasil.

***** Graduada em Engenharia de Produção na Faculdade de Engenharia - FAEN/UFGD, Brasil.
} 
agribusiness, especially within the context of grain exported and productivity. The commercialization of soybean exports in the state of Mato Grosso do Sul is investigated through an exploratory and descriptive research, interviews by semi-structured questionnaires and analyses of secondary data. Results show the importance of strategy used by commercial enterprises (focus on the client) for relationships with producers. Price is one of the most crucial factors in business for the agro-industrial and cereal producers, where the variation of a cent defines buying or not.

KEY WORDS: Mato Grosso do Sul; Soybean; Commercialization.

\section{INTRODUÇÃO}

O agronegócio nacional representa uma das maiores fontes geradoras de riquezas no país, responsável por cerca de 30\% do Produto Interno Bruto (PIB). As projeções do Ministério de Agricultura e Pecuária - Mapa (2012) apontam que o Brasil será o maior país agrícola do mundo em dez anos, sendo que a produção de grãos deverá passar de 153,3 milhões de toneladas em 2011/2012 para 185,6 milhões em 2021/2022. Isso indica o acréscimo de 32,3 milhões de toneladas, à produção atual do Brasil, 21\% em valores relativos. Diante desta conjuntura, a cultura da soja tem destaque pela sua consolidação na região Centro-Oeste do país, pois apresentou nos últimos anos significativa expansão da área ocupada, investimentos e reais ganhos de rendimentos.

O mercado mundial absorve $86 \%$ da produção brasileira para processamento industrial, $7 \%$ para produção de sementes e, $7 \%$ para alimentação humana. No continente asiático, Japão e China destacam-se no mercado mundial pela demanda de grãos e utilizam entre $20 \%$ e $25 \%$ para o consumo humano, enquanto no Brasil, Estados Unidos, União Europeia e Argentina o consumo é menor que $0,1 \%$ (CANZIANI, 2009).

As exportações de soja em grão do Brasil na safra 2012/13 superaram, pela primeira vez, o volume processado pelas indústrias, que reclamam da carga tributária sobre a atividade de esmagamento. A exportação brasileira de soja no ano comercial de fevereiro de 2013 a janeiro de 2014 foi de 43 milhões de toneladas, contra um processamento de 35,4 milhões de toneladas, conforme relatório da Associação 
Brasileira das Indústrias de Óleos Vegetais (ABIOVE, 2014).

A competitividade cada vez maior entre as empresas exige dos gestores uma atenção especial aos componentes que formam o preço final do produto, fazendo com que as empresas cada vez mais demonstrem preocupação quanto à carga tributária inerente a sua atividade. Segundo Junior (2011), a lei Kandir ${ }^{1}$ facilitou as exportações dos produtos primários, provocando uma reestruturação das empresas esmagadoras de soja à medida que a isenção de impostos acabou aumentando as margens de lucro na comercialização in natura e diminuindo a rentabilidade dos produtos beneficiados pela agroindústria. Este novo cenário fez com que permanecessem no mercado as empresas de grande porte e mais eficientes, intensificando as fusões e aquisições no setor agroindustrial.

As consecutivas taxas de crescimento da região Centro-Oeste geram desarmonia na capacidade de processamento, pois caso não haja alguma alteração na legislação tributária, os investimentos em infraestrutura de processamento local serão comprometidos. Aliado a isso, os produtores passaram a necessitar de mecanismos de comercialização mais sofisticados, flexíveis e com menor risco de mercado, incumbidos de aprimorar seus acessos às informações mercadológicas para melhor negociação, no viés da criação de inteligência competitiva de comercialização de grãos (PINAZZA, 2007).

Além disso, na atual estrutura regulatória, o Estado é o agente que tem responsabilidade sobre a totalidade da carga tributária da commodity soja. A arrecadação tributária incidente sobre a exportação tem como principais impostos: imposto sobre operações relativas à circulação de bens e serviços (ICMS), programa de integração social do trabalhador - PIS e contribuição para o financiamento da seguridade social (Cofins) (REZENDE, 2004).

Diante deste cenário, este artigo tem por objetivo caracterizar o processo de comercialização da soja exportada no Estado de Mato Grosso do Sul.

1 Lei Kandir (lei complementar $n^{\circ} 87$, de 13 de setembro de 1996) regulamentou a aplicação do Imposto sobre Operações Relativas à Circulação de Mercadorias e Prestações de Serviços de Transporte Interestadual, Intermunicipal e de Comunicação (ICMS), isentando do pagamento de ICMS sobre as exportações de produtos primários e semielaborados ou serviços. Disponível em: < http://www12.senado.gov.br/noticias/ entenda-o-assunto/lei-kandir >. Acesso em: 15 fev. 2014. 


\section{COMERCIALIZAÇÃO DA SOJA}

A soja após a produção e colheita pode ser entregue nas cooperativas, cerealistas, indústrias de esmagamento ou armazenada na propriedade. Armazenar o produto é uma prática comum e geralmente ocorre para atender a demanda pela sazonalidade do produto, pois em determinada época do ano há grande oferta. Por exemplo, na época de safra os preços tendem baixar, pelo grande volume ofertado. Azevedo (2001) afirma que a comercialização não deve ser aleatória, mas seguir critérios de eficiência econômica para que ocorra a melhor forma de comercialização possível.

Guimarães (2009) apresenta três alternativas de comercialização para produtos agropecuários, incluindo a soja na forma in natura, que são: venda na época da colheita, venda antecipada e estocagem para especulação. O produtor pode utilizar de forma diferenciada cada uma dessas alternativas, assim como realizar uma combinação entre as mesmas com o intuito de reduzir riscos e garantir um determinado valor de venda.

Segundo Agnol et al. (2007), a comercialização da soja no Brasil está dividida entre as empresas processadoras que adquirem cerca de dois terços da produção de grãos, sendo que as quatro maiores são Bunge, ADM, Cargill e $\mathrm{LDC}$; no outro grupo estão as cooperativas que compram a soja diretamente do produtor e realizam o processo de esmagamento ou negociação no mercado externo, por meio da Bolsa de Mercadorias e Futuros (BM\&F) e em outro grupo as denominadas traders que compram dos produtores e de outros intermediários e repassam o grão para indústrias de alimentos, rações ou exportação.

Para Ampessan (2008), os principais fatores que afetam a oferta da soja são extensão de área plantada, produtividade, clima, volume de produção, novas tecnologias, decisões governamentais, logística e produção mundial. Tratando-se de demanda tem-se o volume de esmagamento, a exportação, os estoques iniciais e finais, a demanda pelos produtos derivados, o ritmo da produção de carnes e câmbio. Ainda, segundo o autor, estes fatores, ao se confrontarem, geram pressões positivas e negativas no mercado, o que resulta em cotações ascendentes ou descendentes. No mercado da soja, pelo volume que representa e pela transparência 
das informações, a cada pequeno espaço de tempo, por vezes frações de segundo, as cotações são alteradas pelas operações nas bolsas de valores, influenciando o mercado físico e de futuros.

Para Abreu, Forigo e Zago (2010), os principais meios de comercialização da commodity soja são por meio da Bolsa de Mercadorias e Futuros (BM\&F) e da Chicago Board of Trade (CBOT) $)^{2}$. Os operadores da empresa utilizam os mecanismos dessas bolsas para negociarem contratos de soja em dólar. Estes operadores utilizam softwares específicos que demonstram as várias cotações existentes, referentes aos ativos negociados. Baseados nessas informações e em tendências do mercado, ordens de compra e venda são passadas a empresas corretoras, que repassam essas mesmas ordens às bolsas citadas.

São várias as ferramentas que podem ser utilizadas para o controle das ordens passadas, como também são vários os softwares (SAP, Oracle, BI - Business Intelligence) para a verificação dos diversos valores das opções, tanto de compra, quanto de venda. Isso possibilita o acompanhamento de várias cotações de diversas commodities ao mesmo tempo, bem como a construção de gráficos de acompanhamento e evoluções históricas.

Flutuações nas variáveis econômicas e financeiras, tais como taxas de câmbio, taxa de juros e preço das commodities, têm produzido efeito desestabilizador nas estratégias empresariais e nos resultados das empresas. Dessa forma, as operações de proteção têm por função minimizar este efeito desestabilizador buscando otimizar o retorno por unidade de risco (ABREU; FORIGO; ZAGO, 2010).

Para Savelli (2009), é com essa função de fornecer proteção às operações financeiras que o bedge torna-se uma opção. Com essa ferramenta os operadores do mercado financeiro podem minimizar o risco de perdas (juros a pagar, variações negativas de câmbio), por meio de procedimentos realizados em bolsas de valores. Essa é uma forma de realizar um seguro para estabelecer um limite para eventuais prejuízos. O bedge possui vital importância para aqueles que realizam operações com moeda estrangeira, principalmente para a tomada de recursos.

Em geral, as operações de hedge são realizadas na Bolsa de Mercadorias e Futuros. Assim, se uma empresa possuir dívidas em dólares e quer se prevenir de

2 A Chicago Mercantile Exchange (CME) trabalha com vários tipos de instrumentos financeiros: taxas de juros, ações, moedas e commodities. Também oferece negociação em investimentos alternativos, como derivativos pós e pré-fixados. É a maior bolsa do mundo no mercado de opções e contratos futuros de juros abertos em número de contratos custodiados. 
eventual alta da moeda norte-americana, esta empresa vai até a BM\&F e compra um contrato de dólar futuro, garantindo que, em determinada data, poderá comprar determinada quantia de dólares a determinada cotação. Se o dólar ultrapassar a cotação fixada, a empresa estará protegida, pois terá o direito a comprar a moeda a um preço mais baixo. Entretanto, operações como esta tem um custo, por isso são feitas por empresas ou bancos (SAVELLI, 2009).

De acordo com Schouchana (1997), as principais condições para que uma mercadoria possa ser negociada no mercado futuro:

a) o produto deve ser passível de padronização e não pode ser perecível;

b) a mercadoria deve permitir a formação de lote padrão, uniforme;

c) deve existir grande oferta do produto com forte competição entre ofertadores e demandadores, sem qualquer interferência por parte do governo ou oligopólios;

d) a oferta e a demanda devem ser incertas, pois, só assim, os preços flutuarão e existirá o risco. Os hedger's precisarão de proteção contra tais riscos. Assim se cria uma fonte de (possíveis) ganhos para os especuladores - que tentarão tirar proveito das oscilações das cotações.

\section{MERCADO E CANAIS DE ESCOAMENTO DAS EXPORTAÇÕES}

A exportação é uma atividade importante para as empresas, pois abre um leque maior de possibilidades para as negociações de seus produtos, que além de serem comercializados no mercado interno, passam a ganhar espaço no mercado externo, diminuindo a sazonalidade do produto. De acordo com o Instituto de Estudo do Comércio e Negociações Internacionais (ICONE, 2011), a China e a União Europeia são os principais destinos da soja in natura exportada do Brasil. Embora, no período de 2001 a 2011, as importações chinesas cresceram $280 \%$ enquanto as europeias diminuíram 30\%. Segundo Silveira (2005), com uma produção aproximada de 16 milhões de toneladas de soja e aumento das indústrias esmagadoras, ainda não é suficiente para atender a demanda interna de óleo comestível na China. 
Quanto ao transporte do grão da commodity soja na região Centro-Oeste, Timossi (2003) afirma que é realizado por meio rodoviário até os principais portos brasileiros, em estradas de rodagem, por caminhões, carretas e treminhões.

O principal corredor, na região Centro-Oeste, para escoar a soja de Mato Grosso do Sul é a BR 163, que possui ao todo $3.467 \mathrm{~km}$ de extensão, integrando os Estados do Pará, Mato Grosso, Mato Grosso do Sul, Paraná, Santa Catarina e Rio Grande do Sul. O corredor logístico é um sistema integrado que utiliza de vias, veículos, centros de armazenagens e portos, possibilitando meios racionais e a menores custos o escoamento da produção agrícola.

Segundo Casarotto et al. (2013), 60\% da soja no Brasil são transportadas por rodovias, sendo que nos Estados Unidos, apenas 13\% utilizam este modal. Os autores ainda citam que a função do corredor no transporte de grãos é proporcionar meios para escoar a produção do produtor ao destino final, no caso da soja às agroindústrias ou um porto exportador. A falta de alternativas para escoar a produção submete-se ao uso tão somente de rodovias que, além de reduzir a competitividade, aumenta os custos logísticos que decorrem das estradas em mau estado de conservação e perdas de grãos no transporte.

Uma alternativa ao transporte rodoviário no Estado seria o investimento no modal ferroviário. Neste sentido, algumas ações governamentais começam a ser executadas na tentativa de viabilizar esta alternativa. Em 2013, Mato Grosso do Sul foi contemplado com aproximadamente $\mathrm{R} \$ 4,2$ bilhões, por meio do Programa de Aceleramento do Crescimento (PAC), para investimentos na malha ferroviária com concessão à iniciativa privada que será por 35 anos e previsão da conclusão das obras no ano de 2019, contemplando sete municípios: Brasilândia, Santa Rita do Pardo, Bataguassu, Nova Andradina, Deodápolis, Angélica e Dourados. Além de facilitar o escoamento da produção de grãos no Estado, a intenção dos investimentos é promover o desenvolvimento econômico da região, visto que se produz também etanol, carne, celulose, fertilizantes e outros (IFATO, 2013).

De acordo com Vencovsky (2011), mais de 63\% das exportações de grãos de soja se concentram nos portos de Paranaguá e Santos. Os maiores exportadores de soja no Brasil, bem como outros de menor porte, investem na infraestrutura de alguns portos (terminais de armazenagem, equipamentos para recepção dos grãos e 
para carregamento de navios etc.). As empresas que não possuem terminais próprios dispõem de infraestrutura nos terminais públicos (de propriedade da União) ou alugam espaço em privativos mistos.

\section{FATORES ESTRATÉGICOS}

A forte disputa entre as empresas do agronegócio fez com que as mesmas se voltassem à busca de estratégicas que as diferenciassem e as tornassem competitivas. Deste modo, conhecer os fatores que influenciam o mercado e a utilização estratégias que consistem em estimar preços futuros de curto, médio e longo prazo, por meio dos canais de comercialização disponíveis tornaram-se mecanismos fundamentais de diferenciação frente à concorrência. Além disso, diante de um mercado dinâmico e de risco, o uso das ferramentas disponíveis de planejamento estratégico tornou-se imprescindível para orientar a tomada de decisão (CANZIANI, 2009).

Segundo Haguenauer, Ferraz e Kupfer (1996, p. 196), competitividade é definida "[...] como a capacidade da empresa formular e implementar estratégias concorrenciais, que lhe permitam ampliar ou conservar, de forma duradoura, uma posição sustentável, no mercado".

As empresas precisam ter vantagens competitivas relacionadas a menores custos de produção, produtos diferenciados e enfoque nos segmentos que decidir atender para criar uma cadeia de valor. Para Porter (1993), as organizações fortalecidas pela rivalidade no mercado interno estão mais preparadas para obter sucesso no mercado externo, pois onde existe um mercado interno forte e competitivo, as empresas locais não apenas melhoram suas vantagens internas, como são pressionadas a competir no exterior.

\subsection{TIPOS DE ESTRATÉGIAS}

As estratégias podem ser competitivas, de crescimento, genéricas, entre outras. Porter (1991) alerta que, quando uma empresa se confronta com as cinco forças competitivas, há três estratégias de caráter genérico passíveis de serem bemsucedidas: liderança no custo total, diferenciação e enfoque. 
A estratégia de liderança no custo total é quando a empresa consegue obter custos mais baixos em relação aos concorrentes. A estratégia de diferenciação relaciona-se à disponibilidade de bens ou serviços com características superiores ou mais atraentes, para que os clientes os percebam como valor maior do que as alternativas do mercado e os escolham. Já a estratégia de foco consiste em concentrar a atenção da empresa em uma parcela restrita do mercado, um nicho que ela tenha condições de atender melhor com preços mais baixos que a concorrência (PORTER, 1993).

Não menos importante, mas com aplicabilidade atenuada, as estratégias por liderança no custo total e diferenciação são ínfimas, pelas commodities serem homogêneas, de qualidade quase uniforme e de baixo valor agregado, com dependência de outros fatores externos como demanda e especulações do mercado, mas estas estratégias são intrínsecas à estratégia focada ao cliente.

Para Zaccarelli (1996), vantagem competitiva pode ser qualquer característica de produtos ou serviços ofertados, que os clientes consigam reconhecer como diferencial positivo em relação ao demais concorrentes. Assim, considerando a importância do cliente, para uma empresa se manter competitiva no mercado, necessita-se utilizar uma estratégia focada no cliente, em que necessidades e desejos são compreendidos e empregados para se obter vantagens competitivas frente à concorrência. Essa ideia é reforçada por Pizzinatto et al. (2005, p.11), ao afirmarem que o foco no cliente materializa-se "nos benefícios adicionados aos produtos e serviços, diferenciando-os pela agregação de valor que, sob a ótica do cliente, os torna superiores às vantagens da concorrência".

\subsubsection{Tributação}

A política de concessão de incentivos fiscais do governo federal visando aumentar a competitividades de alguns setores econômicos, bem como fomentar o desenvolvimento regional, merece maior atenção de estudos no âmbito da ciência política. Desde meados da década de 1960 até o começo da década de 1980, os incentivos fiscais foram instrumentos importantes, tanto da política industrial então vigente - de industrialização por substituição de importações -, quanto da política de desenvolvimento regional (MACIEL, 2009). 
Lazzarotto e Roessing (2008) citam que dentre os países do Mercosul e União Europeia, o Brasil detém a maior carga tributária do setor agroindustrial, enfatizam, também, que os principais impostos que incidem sobre os alimentos são o imposto sobre operações relativas à circulação de bens e serviços - ICMS, o programa de integração social do trabalhador - PIS e a contribuição para o financiamento da seguridade social - Cofins.

No que se diz respeito aos impostos como um dos componentes que interfere no processo de exportação, Riani e Albuquerque (2008) e Junior (2011) ressaltam que a lei Kandir isentou o pagamento de ICMS sobre as exportações de produtos primários e semielaborados ou serviços em setembro de 1996, com o objetivo de incentivar as exportações brasileiras, promover o crescimento econômico e melhorar o saldo da balança comercial, bem como elevar os investimentos internos.

A lei Kandir beneficiou a exportação de matéria-prima, contribuindo para o Brasil tornar-se um dos maiores exportadores de soja do mundo, no entanto reduziu a competitividade do sistema agroindustrial brasileiro diante dos concorrentes mundiais, gerando retração de postos de trabalhos no setor agroindustrial nacional, transferindo a geração de empregos aos países compradores da soja em grãos produzida no Brasil (CALDARELLI; CAMARA; SEREIA, 2009).

\section{METODOLOGIA}

Este artigo caracteriza-se por ser de caráter exploratório - descritivo. Segundo Gil (2008), a pesquisa exploratória tem como objetivo proporcionar uma visão geral de um determinado fato, esclarecer conceitos e ideias, tendo em vista a formulação de hipóteses pesquisáveis para estudos posteriores. O caráter descritivo da pesquisa se dá em razão da mesma descrever os processos e decisões no ato da comercialização das principais negociadoras de soja no Estado de Mato Grosso do Sul. No desenvolvimento da pesquisa foram utilizadas técnicas de investigação documental, estudo de campo e análises de dados secundários. Utilizou-se um questionário semiestruturado, composto por 13 questões, sendo abertas e fechadas. De acordo com Vergara (2007), a investigação documental é realizada em 
documentos conservados no interior de órgãos públicos e privados de qualquer natureza, ou com pessoas, sendo, registros, anais, regulamentos, circulares, ofícios, memorandos, balancetes, comunicações informais, entre outros. Para facilitar a organização dos resultados, as questões foram estruturadas em grupos, conforme segue: grupo 1 - informações de mercado; grupo 2 - fatores de negociação; grupo 3 - tributação e grupo 4 - estratégias.

Foram distribuídos dez questionários aos gestores das principais comercializadoras de grãos no Estado, entregues pessoalmente ou através de e-mail. Destas, oito gestores retornaram. Após avaliar a representatividade no mercado de cada empresa, definiu-se como objeto de pesquisa sete empresas, sendo três agroindústrias multinacionais (Empresa A, C e D) e mais três cerealistas nacionais agrupadas como Empresa C. As cerealistas escolhidas não possuem vínculo entre si, são distintas e comercializam de forma independente, assim como não processam o produto, apenas fazem a comercialização e estocagem, desta forma diferenciandose das demais empresas A, C e D, que são agroindústrias e também comercializam soja para exportação. A pesquisa de campo realizada com as empresas selecionadas ocorreu no período de abril a maio de 2014.

$\mathrm{Na}$ apresentação dos resultados são atribuídos nomes fictícios às quatro empresas participantes sendo seis unidades pesquisadas, conforme segue: Empresa A, Empresa B, Empresa C e Empresa D. Considera-se a Empresa B o grupo das três cerealistas comercializadoras de grãos no Estado.

Os dados primários foram coletados por meio de pesquisa de campo com observação participante para identificação das atuais estratégias de comercialização para exportação. Para os dados secundários foram utilizadas diversas fontes de informações, por meio de consultas em bases acadêmicas, mídias locais, bem como web sites do governo federal e estadual.

Para determinar quais empresas- alvo da pesquisa, levou-se em consideração o volume exportado na safra 2012/13 conforme pesquisa empírica realizada na empresa que foi aplicado o pré-teste, como também informações das mídias locais. $\mathrm{O}$ resultado mostra que, juntas, as três empresas agroindustriais, representadas por Empresa A, C e D, e o grupo composto por três cerealistas (Empresa B), concentram $83 \%$ do volume exportado no Estado. 
As informações por empresas foram obtidas por meio da pesquisa de campo, pois os dados divulgados nos órgãos oficiais como MDIC e outros, não são detalhados. É possível verificar o valor monetário exportado por empresa, porém não por produto. Além de exportar a soja, grande parte das empresas negociadoras de grãos também exportam farelo de soja, óleo de soja e outros produtos como milho e algodão, que contemplam o montante monetário exportado.

\section{RESULTADOS: APRESENTAÇÃO E DISCUSSÃO}

\subsection{INFORMAÇÕES DE MERCADO}

De acordo com Mendes (1994), a função de informação de mercado diz respeito à coleta, interpretação e disseminação de dados com o intuito de facilitar a comercialização, porém a informação deve ser atual e confiável.

Todos os entrevistados citam que sua maior fonte de informações provém diretamente dos produtores rurais, mídias, governo e outras empresas negociadoras, conforme Gráfico 2. No quesito eventos, palestras, exposições e troca de informações com a concorrência, apenas a Empresa B se utiliza destas fontes, justamente pelo seu perfil de comercialização ser diferente das agroindustriais.

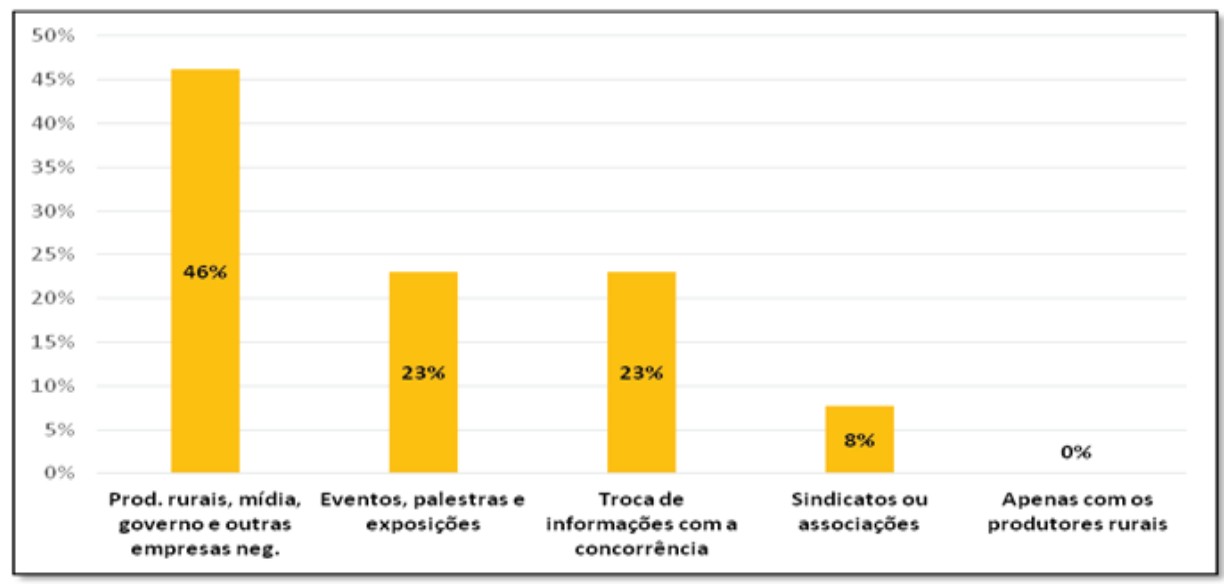

Gráfico 2. Principais fontes de informação de mercado

Fonte: Elaborado pelos autores a partir de dados da pesquisa de campo - 2014 
Eventos agropecuários representam uma oportunidade para aproximar os produtores rurais, mídia, governo e empresas negociadoras. Um dos eventos que acontece no Estado é o Showtec, realizado pela Fundação MS no mês de janeiro em Maracaju. Em 2014, o evento recebeu 13 mil visitantes e 130 expositores, sendo considerada uma das dez maiores feiras do setor. Possui uma programação técnica científica diversificada, incluindo demonstrações de novas tecnologias e palestras específicas sobre os diferentes setores do agronegócio.

\subsection{FATORES DE NEGOCIAÇÃO}

Neste tópico procura-se identificar os principais fatores de negociação que influenciam as tomadas de decisões na negociação da soja para exportação. Foram avaliados o fator determinante, o período, o volume, a capacidade estática, a negociação com a concorrência, os destinos e portos utilizados no escoamento da produção. Os resultados são apresentados no Gráfico 3.

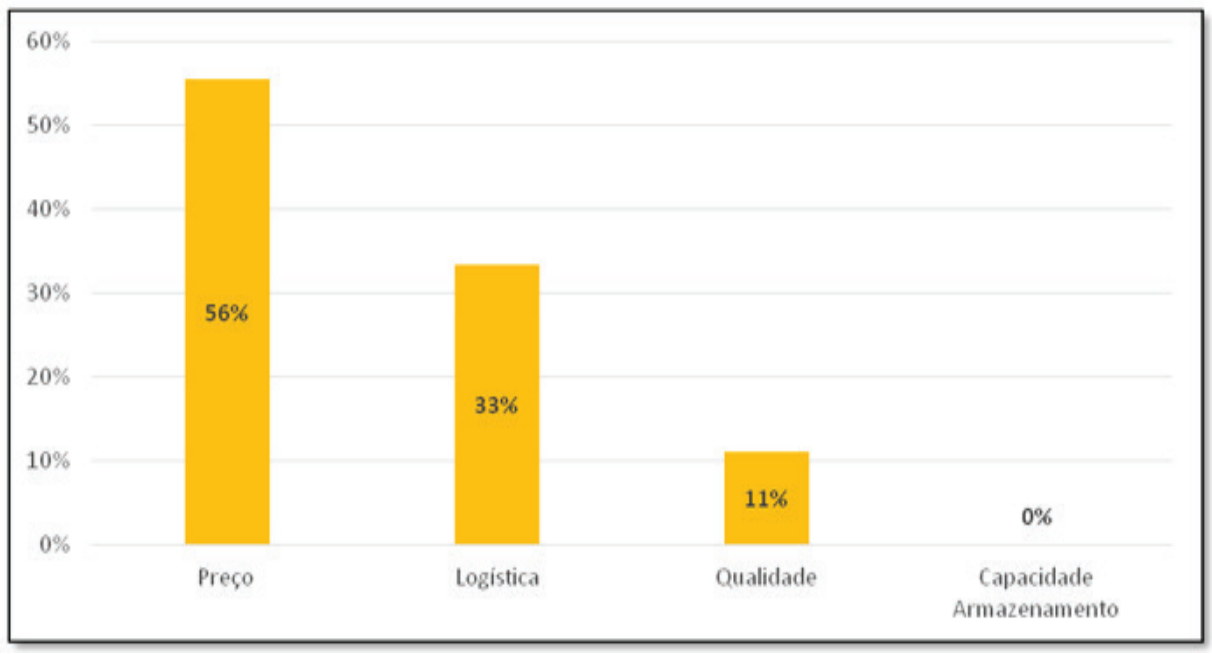

Gráfico 3. Fatores determinantes para compra e venda de soja para exportação

Fonte: Elaborado pelos autores a partir de dados da pesquisa de campo - 2014

Os dados indicam que o preço é o principal fator determinante no momento da compra ou venda. A soja por ser uma commodity e o seu preço ser regulado 
por vários fatores externos como bolsa de valores, políticas externas, câmbio, clima, tecnologia e outros, torna a concorrência acirrada entre as empresas, em que a diferença de centavos pode gerar grande impacto financeiro num volume maior quando negociado.

O auge da comercialização da soja no Estado ocorre no segundo trimestre do ano, quando o Estado atinge o maior volume de exportações. Segundo os entrevistados é neste período que a oferta aumenta, forçando muitos produtores a venderem sua produção pela falta de local para armazenagem ou para aproveitar o bom momento do mercado.

De janeiro a abril ocorre o período de colheita da soja no Estado, sendo mais intenso no período de fevereiro a março. De maio a junho a produção destinada para exportação atinge seu auge de escoamento. De julho até a primeira quinzena de setembro ocorre o vazio sanitário, período que é proibido o plantio de soja nos Estados do MT, MS, GO, TO, SP, MG e MA, a fim de evitar a ferrugem asiática. O plantio ocorre a partir da segunda quinzena de setembro até dezembro.

Segundo dados da Conab (2014b), a produção de soja no Estado de Mato Grosso do Sul, na safra 2012/13, foi de 5.809 mil toneladas, um acréscimo de 25,5\% em relação à safra anterior que produziu 4.628 mil toneladas. De acordo com o MDIC (2014), da produção de soja sul-mato-grossense, 39\% foram destinados à exportação, representando um volume de 2.280 mil toneladas e o restante $61 \%$ destinado a outros fins.

Do volume produzido para exportação, foi comercializado pelas principais negociadoras pesquisadas, conforme Tabela 1 .

Tabela 1. Volume (mil ton.) exportado por empresa. Safra 2012/13

\begin{tabular}{|c|c|c|}
\hline Empresa negociadora & Volume & Acum. \% \\
\hline Empresa A & 596 & 26 \\
\hline Empresa $\mathrm{B}^{1}$ & 495 & 48 \\
\hline Empresa C & 471 & 69 \\
\hline Empresa D & 325 & 83 \\
\hline OUTRAS & 393 & 100 \\
\hline TOTAL & & \\
\hline
\end{tabular}

Fonte: Elaborada pelo autor a partir de dados da pesquisa de campo (2014)

Nota $^{1}$ : Volume exportado por cerealista: Cerealista 1: 187 mil ton., Cerealista 2: 162 mil ton. e Cerealista 3: 146 mil ton. 
Segundo os gestores entrevistados, o volume exportado é considerado bom, apesar da dificuldade de escoamento, uma vez que a produção para chegar aos principais portos, percorre um longo trajeto por vias rodoviárias por meio de outros Estados brasileiros.

Durante a safra, os produtores precisam de locais para armazenar a produção e o Estado possui aproximadamente 7.796 mil toneladas de capacidade estática de armazenagem de carga a granel (CONAB, 2014a). A produção total de grãos do Estado, na safra 2012/13, foi de 13.914 mil toneladas. Subtraindo a produção da capacidade estática, encontra-se um déficit de 6.118 mil toneladas de capacidade de armazenagem.

Esse déficit prejudica o elo da cadeia formado pelos produtores rurais, que muitas vezes são forçados a negociar a produção no auge da colheita, obtendo preços mais baixos pelo produto e custos de transporte mais altos em virtude da falta de armazéns (ALVES, 2005). Alguns produtores rurais possuem armazenagem própria e aproveitam-se disso para aguardar o melhor momento de negociar a safra, consequentemente se beneficiando da melhora nos preços ao final da mesma.

As empresas pesquisadas possuem juntas cerca de $23 \%$ de capacidade de armazenagem do Estado. As empresas A, C e D utilizam esta capacidade para estocar a soja para esmagamento e extração do óleo bruto, ou como um ponto de transbordo para, posteriormente, concentrar o volume em unidades maiores próximas aos portos. A empresa B utiliza sua capacidade para receber e beneficiar a soja do produtor rural.

Mesmo com déficit na capacidade estática de armazenamento no Estado, as empresas pesquisadas alegam que durante o pico da safra, que ocorre geralmente no segundo trimestre do ano, o fluxo de escoamento da soja aumenta e os armazéns, muitas vezes, não chegam a sua capacidade máxima.

Os gestores das empresas afirmam que negociam com o produtor rural, com outras empresas negociadoras de grãos, sendo que as cooperativas agropecuárias possuem $43 \%$ de participação nas negociações com as empresas pesquisadas. As cooperativas agropecuárias são compostas por produtores rurais que se beneficiam da compra em comum de insumos, a venda em comum da produção dos cooperados, a prestação de assistência técnica, armazenagem, industrialização, entre outros (COOPERALIANÇA, 2014). 
Em relação aos portos utilizados para escoar a produção de soja do Estado na safra 2012/13. Dos participantes da entrevistada, 40\% utilizam o porto de Paranaguá, 30\% porto de Santos, 20\% porto de Rio Grande e 10\% o porto de São Francisco para escoar a soja comercializada para exportação no Estado (Gráfico 4).

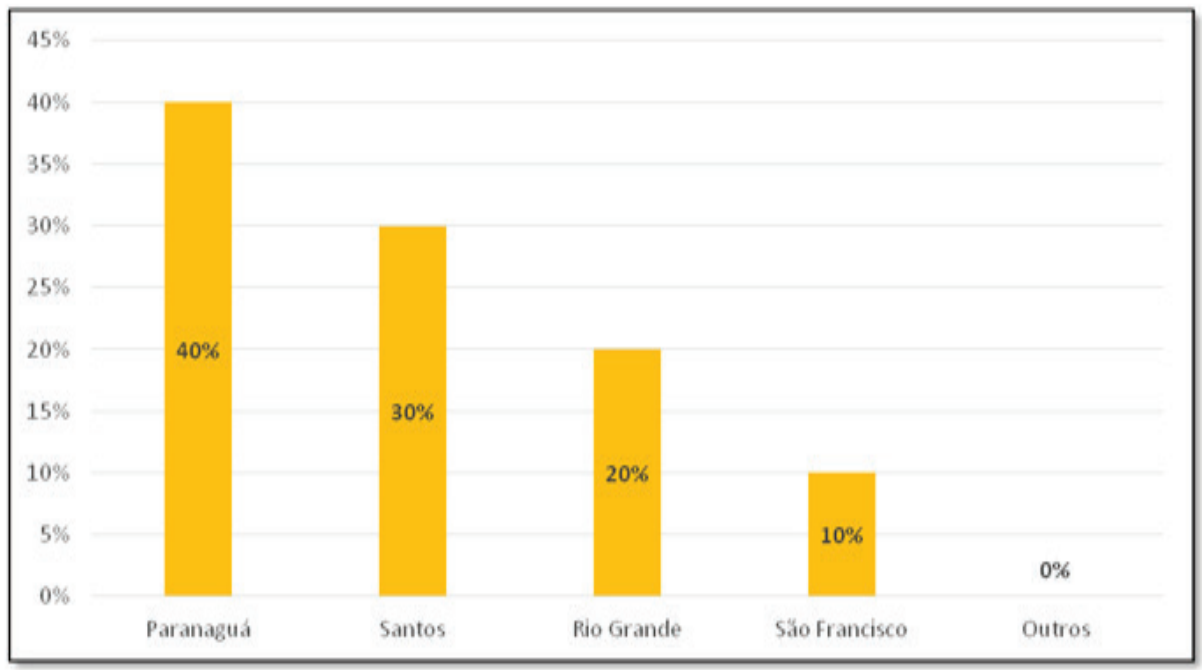

Gráfico 4. Portos para escoamento da soja de MS - Safra 2012/13

Fonte: Elaborado pelos autores a partir de dados da pesquisa de campo - 2014

É possível observar que o porto de Paranaguá, no Estado do Paraná, é o mais utilizado para escoar a produção do Estado. As empresas utilizam os portos conforme estrutura própria disponibilizada e também avaliam a lotação e ociosidade dos navios. As empresas não divulgaram os volumes que exportam por porto, impossibilitando a comparação dos resultados.

Do volume exportado da soja no Estado de Mato Grosso do Sul na safra 2012/13, 85\% foram destinados à China, que importa soja brasileira por questões estratégicas, investindo no processamento da matéria-prima em seu território (ALICEWEB, 2014). Percebe-se como o mercado de commodities é importante para o país, porém expõe a fragilidade da dependência de um grande importador. Uma crise nas relações comerciais com a China poderia desencadear grandes problemas ao agronegócio sul-mato-grossense. 


\subsection{TRIBUTAÇÃO}

Em relação à tributação, quatro empresas concordam que o Estado oferece condições igualitárias de concorrência aos demais Estados brasileiros, porém com algumas observaçóes. De acordo com o gestor da empresa A, existem programas direcionados aos pequenos produtores, por exemplo, o Senar/MS que apoia a agricultura familiar, onde a união destes gera um volume de grãos considerável quando armazenados em cooperativas. Para o da empresa B ainda são ofertadas linhas de créditos como FCO Rural e BNDES. Além disso, todos os gestores foram enfáticos ao afirmar que a alta carga tributária dificulta a expansão dos negócios e investimentos no Estado.

Quando questionados se suas empresas possuíam benefícios fiscais do Estado para comercializar e exportar a soja, quatro relataram que não. Outros dois responderam sim, possuem redução e deferimento de impostos estaduais e municipais, mas, por questões estratégicas, não citaram quais seriam esses impostos e taxas.

A falta de informações sobre impostos e benefícios fiscais que as empresas desfrutam não é um problema apenas de Mato Grosso no Sul. Segundo Bertolini (2014), ao questionar o secretário Estadual de Indústria, Comércio, Minas e Energia do Estado de Mato Grosso sobre a divulgação das empresas beneficiadas pelas políticas de incentivos fiscais, o secretário disse que "[...] a lei não permite". $\mathrm{O}$ autor ainda cita que em se tratando de política pública, as informações estão sujeitas a acompanhamento e avaliação por parte do governo como pela sociedade. Durante a elaboração desta pesquisa, não foram encontradas, em pesquisas nos sites do governo estadual de Mato Grosso Sul, informações sobre benefícios fiscais e relação das empresas que os usufruem.

Mesmo a lei Kandir isentando do pagamento de ICMS sobre as exportações de produtos primários e semielaborados ou serviços, a maior produtividade e menores custos de produção mantêm a competitividade diante dos concorrentes internacionais. Todavia, as tentativas do Poder Público de desoneração tributária nas etapas iniciais da cadeia produtiva não têm sido suficientes para reerguer os segmentos mais prejudicados com fatores climáticos e econômicos internacionais, 
atravancando o crescimento da produção e exportações. Destarte, é essencial que os produtores rurais, empresas, associações, sindicatos e outros interessados estejam atentos à carga tributária incidente sobre a produção das commodities agrícolas, de forma que possam planejar suas atividades a fim de minimizar os impactos dos excessivos custos tributários a que estão submetidos os produtos agropecuários e todas as etapas da cadeia produtiva (produção e comercialização).

\subsection{ESTRATÉGIAS DE COMERCIALIZAÇÃO}

Ao utilizar a estratégia voltada ao cliente, as empresas levam em consideração as metas e recursos disponíveis, cabendo ao tomador de decisão conhecer o máximo possível do mercado onde está inserido. As empresas procuram obter informações do passado e futuras do mercado para identificar o melhor momento para realizar as negociações, de forma a aproveitar as oportunidades oferecidas. Conhecer os instrumentos de comercialização e sua utilização tornam os negociadores melhores preparados para enfrentar um mercado tão dinâmico quanto das commodities.

O Brasil e consequentemente o Estado de Mato Grosso do Sul é considerado price traker, ou mais conhecido como tomador de preço. Segundo Bueno (2011), o termo price traker refere-se à situação onde o mercado submete-se como referência os preços estabelecidos nas praças internacionais de exportação e não tem condições de influenciá-los. Comercializar no mercado de commodities exige dos negociadores adquirirem conhecimento sobre o comércio mundial, mercado cambial, questões tributárias e outros fatores exógenos que influenciam na tomada de decisões.

Os entrevistados buscam constantemente fortalecer o relacionamento com o produtor rural, por meio de reuniões, visitas, oferta de crédito para financiamento, utilizando-se da credibilidade que a marca da empresa conquistou no mercado ao longo da sua atuação. Por ser um mercado dinâmico, acompanhar o ritmo do mercado é essencial para oferecer oportunidades de negócios lucrativas aos interessados. Na linguagem de mercado, utiliza-se a expressão time, na referência de que se deve aproveitar o momento, não perder o ritmo de negociação do mercado.

A empresa B (grupo de cerealistas) utiliza como diferencial a oferta de insumos e defensivos agrícolas para venda ou troca por grãos. Esta estratégia faz com que ocorra maior aproximação com o produtor rural e aumente o rol de produtos 
e serviços ofertados. Algumas agroindústrias utilizam-se deste modo de atuação via parcerias ou join-venture.

Mesmo que algumas empresas entrevistadas considerem o volume exportado no Estado suficiente, considerando a atual estrutura logística e tecnológica. As mesmas citam que a reforma tributária é fundamental para que se possa aumentar os investimentos no agronegócio sul-mato-grossense, por meio da racionalização e simplificação do sistema tributário, reduzindo a carga tributária com foco na competitividade.

Os gestores entrevistados buscam de forma perene a competitividade no agronegócio sul-mato-grossense, utilizando-se do know-bow adquirido na comercialização de grãos. Outro fator também citado como influenciador na tomada de decisão diz respeito às políticas econômicas que regem o Estado. Segundo Araújo et al. (2013), as políticas econômicas são fatores determinantes do preço e competitividade da comercialização de grãos. Cita como exemplo os insumos, caso seja reduzido às importações poderá aumentar os preços e impactar no custo de produção dos grãos.

Conforme apresentado, o Estado de Mato Grosso do Sul possui alta produtividade na produção de soja, tornando-o competitivo diante dos demais Estados. Neste sentido, do ponto de vista de Araújo et al. (2013) são necessárias medidas mais eficazes para alocar os recursos financeiros do Estado, promover a competitividade do produto por meio de políticas públicas de incentivo para abertura de novas indústrias, infraestrutura, entre outros voltados para o desenvolvimento da economia regional.

\subsection{DISCUSSÃO DOS RESULTADOS}

O mercado de commodities é hoje um dos setores mais dinâmicos da economia brasileira e manter-se competitivo no mercado requer estratégias sinérgicas para competir com a concorrência, deste modo, por meio da pesquisa foi constatada a utilização da estratégia focada no cliente.

Para conhecer o mercado e obter informações, as empresas pesquisadas utilizam como base para tomada de decisões, informações de mercado, dos produtores rurais, da mídia, do governo e de outras empresas negociadoras. Um 
fato interessante em relação ao grupo de cerealistas identificado como Empresa B é que eles também utilizam eventos, palestras e exposições, justamente pelo seu perfil de comercialização ser diferente das agroindústrias.

As cerealistas possuem a segunda maior participação na exportação de grãos no Estado e o seu sucesso deve-se ao fato que os pequenos e médios produtores as procuram pela falta de estrutura de armazenagem e conhecimento do mercado de futuros.

O hedge é uma ferramenta de comercialização essencial para uma gestão de preços eficaz, mas a sua prática exige dos produtores conhecimento mais aprofundado dos períodos ideais para fazer bedge de venda da sua produção. Muito destes produtores não têm conhecimento técnico e não se sentem capacitados para operar com mercado de futuros na BM\&F, assim, por meio das cerealistas conseguem preencher essa lacuna. As cerealistas, por opção, podem negociar com as agroindústrias ou exportar diretamente a produção comercializada. Para atrair e reter os produtores, as cerealistas também oferecem insumos e defensivos agrícolas para venda ou troca por grãos.

As empresas agroindustriais não apenas exportam, mas processam o grão de soja em farelo e óleo, ao contrário das cerealistas que utilizam o grão exclusivamente como meio de comercialização. Uma das vantagens das agroindústrias é que sua capacidade financeira permite oferecer aos vendedores de grãos empréstimos para custear a safra, com taxas até menores que oferecidas pelos bancos, criando uma relação comercial estável e próxima entre as partes. A garantia de compra e pagamento em curto prazo também faz com que cerealistas, cooperativas e produtores rurais procurem as agroindústrias, pois a sua credibilidade, marca e infraestrutura permite atender grandes fornecedores de grãos. Elas também buscam aproximar dos pequenos e médios agricultores, por meio dos eventos que são promovidos no Estado. Uma das formas utilizadas é a participação no Showtec que anualmente promove a divulgação de novas tecnologias para as diferentes áreas do agronegócio.

Seja para as agroindústrias ou cerealistas, o preço é considerado um dos fatores cruciais para a negociação, onde a variação de centavos define a compra de um lote de soja. O fato do mercado brasileiro de commodities de soja ser considerado price traker, limita as margens de negociação no preço da soja, pois 
a base de formação de preço é por meio da bolsa de valores. No caso de Mato Grosso do Sul, os gestores criticam o sistema tributário que segundo eles, afeta os preços e diminui a competitividade, além de impedir o pleno desenvolvimento do agronegócio. Segundo os entrevistados, a carga tributária deve ser compatível com a dos nossos competidores do mercado exterior, pois a atual carga afeta diretamente os preços praticados no mercado.

O corredor logístico no Estado é limitado à rodovia BR 163, ficando os exportadores limitados ao uso de caminhões para transportar a carga até os portos marítimos. Tal limitação, no pico da safra, acarreta aumento de até $30 \%$ nos custos com o transporte. As empresas precisam adaptar-se ao ambiente competitivo estratégico atual, integrando suas atividades. Essa integração assume diferentes configurações dependendo de como os fatores ambientais afetam as empresas envolvidas.

A expectativa é que na próxima década, o sistema ferroviário venha oferecer opção com menor custo para escoar a produção e sugerem-se investimentos de armazenagem próximos às linhas férreas que serão instaladas no Estado. Com respeito aos portos marítimos, fica a sugestão de medidas que reforcem a sua modernização e estimulem seu aumento de capacidade e eficiência, aproximando os portos brasileiros aos padrões internacionais.

Constatou-se neste estudo que existe um déficit de 6.118 mil toneladas de armazenamento de grãos no Estado, forçando os produtores menos estruturados a venderem suas produções impreterivelmente no período da safra, em que os preços diminuem pela grande oferta de grãos no mercado.

\section{CONCLUSÃO}

Este artigo objetivou caracterizar o processo de comercialização da soja exportada no Estado de Mato Grosso do Sul. Os resultados revelam que o mercado no Estado é fortemente coordenado pelos processos de comunicação e informação que envolvem todos os agentes da cadeia, e pela diversidade de agentes e informações, é altamente suscetível assimetria informacional. Tem o fator preço como um dos e, às vezes, o principal fator de negociação, o que acaba por potencializar os 
efeitos danosos da carga tributária e do custo logístico, este último agravado pela precariedade do sistema de armazenamento do Estado e da estrutura física nacional de exportação.

Por fim, sugere-se que, empresas e produtores, invistam na capacidade própria de armazenagem, pois a utilização de estoques como agente precificador na negociação é estratégia competitiva interessante, principalmente no caso da soja. Também, se propõe o desenvolvimento e divulgação de um mecanismo aberto de acompanhamento do escoamento da safra, método já é utilizado individualmente por grandes empresas comercializadoras para direcionar as estratégias de atuação conforme o volume ainda disponível no Estado.

Como continuidade ao estudo, a abordagem do tema benefícios fiscais oferecidos pelo Estado aos exportadores, principalmente em relação à interferência nas estratégias de comercialização das empresas, uma vez que o Estado utiliza dinheiro público para este fim, devendo haver clareza na utilização destas verbas.

\section{REFERÊNCIAS}

ABIOVE - ASSOCIAÇÃO BRASILEIRA DAS INDÚSTRIAS DE ÓLEOS VEGETAIS. Nota à imprensa. Disponível em: < http://www.abiove.org.br > . Acesso em: 16 jun. 2014.

ABREU, L. F.; FORIGO, E. M.; ZAGO, C. A. O hedge como ferramenta para diminuição dos riscos nas operações financeiras de uma cooperativa de agroalimentos. Niterói. 2010. Disponível em: <http://www.excelenciaemgestao. org/Portals/2/documents/cneg6/anais/T10_0229_1249.pdf $>$. Acesso em: 19 jun. 2014.

AGNOL, A. D. et al. O complexo agroindustrial da soja brasileira. C. T., 43. Londrina: Embrapa, 2007.

ALICEWEB. Estatística Brasileira de Exportações e Importações. Disponível em: $<$ http://aliceweb2.mdic.gov.br//consulta-ncm/consultar> . Acesso em: 19 mai. 2014.

ALVES, A. G. M. P. Armazenagem de grãos no Paraná: diagnóstico da situação 
Atual. Curitiba: BRDE, abr. 2005. 37 p. Disponível em: < http://www.brde.com.br/ estudos_e pub/Armazenagem\%20de\%20Gr\%C3\%A3os\%20no\%20Paran\%C3\%A1. pdf > . Acesso em: 20 mar. 2014.

AMPESSAN, S. Redução da exposição do produtor de soja pelo uso de derivativos. Brasília: UNIBEUB - Centro Universitário de Brasília, 2008.

APROSOJA - ASSOCIAÇÃO DOS PRODUTORES DE SOJA DE MATO GROSSO DO SUL. Soja no Brasil; Soja no Mato Grosso do Sul. Disponível em: < http://www. aprosojams.org.br/soja > . Acesso em: 04 ago. 2013.

ARAÚJO, C. G. et al. Análise dos efeitos da intervenção governamental na competitividade da produção de soja em grãos no Mato Grosso do Sul. Gestão \& Regionalidade, v. 29, n. 87, 2013.

AZEVEDO, P. F. Comercialização de produtos agroindustriais. In: BATALHA, M. O. (Org.); Gestão agroindustrial: Grupo de Estudos e Pesquisas Agroindustriais. v. 1. 2. ed. São Paulo: Atlas, 2001. cap. 2, p. 64-99.

BERTOLINI, R. Os Incentivos Fiscais e o Sigilo das Informações. Disponível em: $\quad<$ http://www.sindifiscomt.org/artigo/13/Os-Incentivos-Fiscais-e-o-Sigilo-dasInformacoes $>$. Acesso em: 23 mai. 2014.

BUENO, A. J. T. Formação do preço da soja no Brasil, a partir de parâmetros de exportação. São Paulo: Bolsa de Mercadorias \& Futuros, 2001.

CALDARELLI, C. E.; CAMARA, M. R. G.; SEREIA, V. J. Exportação e competitividade do complexo soja brasileiro e paranaense de 1990 a 2007. Porto Alegre, 2009.

CAMPOS, M. C. O papel do estado brasileiro na expansão do complexo da soja. XII Colóquio Internacional de Geocrítica, 2012. Anais... Disponível em: < http://www. ub.edu/geocrit/ coloquio2012/actas/14-M-Campos.pdf $\geq$. Acesso em: 02 ago. 2013.

CANZIANI, J. R. A administração da empresa rural. In: PERES, F. C. (Org). Programa empreendedor rural. v. 2. Curitiba: SEBRAE/PR; SENAR/PR, 2009. 
CASAROTTO, E. L.; RUHOFF, M. R.; SILVA, M. V.; ZAGO, H. C. Análise situacional das rodovias federais no Mato Grosso Do Sul. In: I Simpósio de Redes de Suprimentos e Logística, 2013 Anais... Dourados: UFGD, 2013.

CONAB - COMPANHIA NACIONAL DE ABASTECIMENTO. Capacidade estática cadastrada. CONAB, 2014a. Disponível em: < http://sisdep.conab.gov.br/ capacidadeestatica/>. Acesso em: 22 mai. 2014.

CONAB - COMPANHIA NACIONAL DE ABASTECIMENTO. Séries históricas. CONAB, 2014b. Disponível em: < http://www.conab. gov.br/conteudos.php?a $=1252 \& \mathrm{t}=2 \&$ Pagina_objcmsconteudos=3\#A_objcmsconteudos $>$. Acesso em: 22 mai. 2014.

COOPERALIANÇA. O que é Cooperativa. Disponível em: <http://www. cooperalianca.com.br/cooperativismo/cooperativa > . Acesso em: 21 mai. 2014.

DUARTE, M. T. Um estudo sobre modelos de previsão de preços no mercado de grão de soja. 2007. 120 f. Dissertação (Mestrado) - Universidade Federal de Uberlândia, Uberlândia, 2007.

EMBRAPA. Tecnologias de Produção de Soja Região Central do Brasil. Disponível em: < http://www.cnpso.embrapa.br/producaosoja/SojanoBrasil.htm > . Acesso em: 04 ago. 2013.

FERRAZ, J. C.; KUPFER, D.; HAGUENAUER, L. Made in Brazil: desafios competitivos para a indústria. Rio de janeiro: Campus, 1996.

GIL, A. C. Métodos e técnicas de pesquisa social. 6. ed. São Paulo: Atlas, 2008

GODOY, C.V. et al. Histórico do vazio sanitário como medida de manejo da ferrugem asiática da soja. EMBRAPA, Londrina, 2006. Disponível em: < http:// www.cnpso.embrapa.br/download/HistoricoVazio.doc > . Acesso em: 01 jun. 2014.

GUIMARÃES, V. D. A. Especificidades do setor agropecuário. In: PERES, F. C. (Org). Programa empreendedor rural. v. 1. Curitiba: SEBRAE/PR; SENAR/PR, 2009. 
IBGE - INSTITUTO BRASILEIRO DE GEOGRAFIA E ESTATÍSTICA. Levantamento Sistemático da Produção Agrícola, 2014. Disponível em: <http://www.ibge.gov. br/home/estatistica/ indicadores/agropecuaria/spa/ > . Acesso em: 21 mai. 2014.

\section{ICONE - INSTITUTO DE ESTUDO DO COMÉRCIO E NEGOCIAÇÕES} INTERNACIONAIS. Análise estratégica para produção de soja responsável no Brasil e na Argentina. 2011. Disponível em: < http://www.ifc.org/wps/wcm/ connect/cd60bf004a96003aad4aedeec99f439e/Soja + Gap + Analysis.portugues. pdf?MOD=AJPERES > . Acesso em: 05 ago. 2013.

IFATO. União aprova ferrovia que contemplará 7 cidades e custará $\mathrm{R} \$ 4,2$ bilhões. IFato - Campo Grande News. Campo Grande, 14 out. 2013. Disponível em: $<$ http://www.ifato.com.br/ noticias/politica/uniao-aprova-ferrovia-que-contemplara7-cidades-e-custara-r-4-2-bilhoes/1624.html\#.U4x-E_ldWSo >. Acesso em: 16 jun. 2014.

JUNIOR, V. J. W. Dinâmicas e estratégias das agroindústrias de soja no Brasil. Rio de Janeiro: Editora E-papers, 2011.

LAZZAROTTO, J. J.; ROESSING, A.C. Arrecadação tributária sobre produtos agrícolas brasileiros. In: CONGRESSO BRASILEIRO DE ECONOMIA E SOCIOLOGIA RURAL, 46., 2008. Rio Branco. Anais... Rio Branco, UFAC, 2008. p. 134-151.

MACIEL, M. S. Dependência de trajetória nos incentivos fiscais: fragmentação do empresariado na reforma tributária. 2009. Dissertação (Mestrado) - Câmara dos Deputados/CEFOR, Brasília, DF.

MAPA - MINISTÉRIO DA AGRICULTURA, PECUÁRIA E ABASTECIMENTO. Brasil projeções do agronegócio 2011/2012 a 2021/2022. Edição 2012. MAPA. Disponível em: $\quad<$ http://www.agricultura.gov.br/ministerio/gestao-estrategica/projecoes-doagronegocio > . Acesso em: 03 fev. 2014.

MDIC - MINISTÉRIO DO DESENVOLVIMENTO, INDÚSTRIA E COMÉRCIO EXTERIOR. Estatísticas. MDIC, 2014. Disponível em: <http://www.desenvolvimento.gov.br/ sitio/interna/interna.php?area $=1 \&$ menu $=3458>$. Acesso em: 19 mai. 2014 . 
MENDES, J. T. Comercialização agrícola. Curitiba: Ed. Universitária, 1994. 100p.

NAKAHODO, S. N.; JANK, M. S. A Falácia da "Doença Holandesa" no Brasil. São Paulo: Instituto de Estudos do Comércio e Negociações Internacionais, 2006. Mimeografado.

PINAZZA, L. A. Cadeia produtiva da soja. Série Agronegócios (Brasil), Ministério da Agricultura e do Abastecimento. IICA, Brasília, DF (Brasil). v. 2, 2007.

PIZZINATTO, N. K. (Org). Marketing focado na cadeia de clientes. São Paulo: Atlas, 2005.

PORTER, M. E. Estratégia competitiva: técnicas para análise de indústrias e da concorrência. 7. ed. Rio de Janeiro: Campus, 1991.

PORTER, M. E. A Vantagem Competitiva das Nações. Rio de Janeiro: Campus, 1993.

REZENDE, F. Integração regional e harmonização tributária: a perspectiva brasileira. Inter-American Development Bank, 2004. Disponível em: <http:// publications.iadb.org/bitstream/handle/11319/2806/Integracao\%20Regional\%20 e\%20Harmonizacao\%20Tributaria\% 20A\%20 Perspectiva\%20 Brasileira. pdf?sequence $=1>$. Acesso em: 29 jun. 2014.

RIANI, F.; ALBUQUERQUE, C. M. P. A Lei Complementar 87/96 (Lei Kandir): balanço de perdas e ganhos e proposta de mudança - O caso de Minas Gerais. 2000.

SAVELLI, A. D. Proteção contra as oscilações de preço das commodities agrícolasmecanismos de Hedge. In: CONGRESSO VIRTUAL BRASILEIRO DE ADMINISTRAÇÃO, 2009.

SCHOUCHANA, F. Introdução aos mercados futuros e de opções agropecuários. São Paulo: BM\&F, 1997.

SECEX - SECRETÁRIA DE COMÉRCIO EXTERIOR. Exportações de Commodities, 2013. Disponível em: <http://www.mdic.gov.br/sitio/interna/interna. 
php?area $=5 \&$ menu $=1955>$. Acesso em: 14 ago. 2013.

SILVEIRA, J. V. F. Estratégia de segmentação de mercado no agronegócio: o caso da inserção da soja transgênica no estado do Paraná. 2005. Dissertação (Mestrado em Engenharia de Produção) - Programa de Pós-Graduação em Engenharia de Produção da Universidade Tecnológica Federal do Paraná,Curitiba, PR.

TIMOSSI, A. J. Grandes mudanças no escoamento de grãos. Agrianual 2003. São Paulo: FNP Consultoria \& Comércio, 2003a, p. 472-78.

VENCOVSKY, V. P. Logística do agronegócio e uso corporativo do território: avaliação das políticas públicas e privadas do sistema ferroviário brasileiro. 2011. Dissertação (Doutorado) - Universidade Estadual de Campinas, Campinas, 2011.

VERGARA, S. C. Projetos e Relatórios de Pesquisa em Administração. 8. ed. São Paulo: Atlas, 2007.

ZACCARELLI, S. B. Estratégia moderna nas empresas. São Paulo: Zarco, 1996.

Recebido em: 2015-11-20 Aceito em: 2017-03-04 